\title{
Numerical investigations of the effect of strain softening on the behaviour of embedded mooring chains
}

Manuscript submitted to Applied Ocean Research

\section{${ }^{1}$ Chao SUN}

Centre for Offshore Foundation Systems

Oceans Graduate School

University of Western Australia

35 Stirling Highway, Crawley

Perth, WA 6009

Australia

Tel: +61 469743231

Fax: +61 864881044

Email: chao.sun@research.uwa.edu.au

\section{${ }^{2}$ Xiaowei FENG, Ph.D.}

Centre for Offshore Foundation Systems

Oceans Graduate School

University of Western Australia

35 Stirling Highway, Crawley

Perth, WA 6009

Australia

Email: xiaowei.feng@uwa.edu.au

${ }^{3}$ Mark Fraser BRANSBY, Ph.D.

Centre for Offshore Foundation Systems

Oceans Graduate School

University of Western Australia

35 Stirling Highway, Crawley

Perth, WA 6009

Australia

Email: fraser.bransby@uwa.edu.au

\section{${ }^{4}$ Steven R. NEUBECKER, Ph.D.}

Centre for Offshore Foundation Systems

Oceans Graduate School

University of Western Australia

35 Stirling Highway, Crawley

Perth, WA 6009

Australia

Email: steven.neubecker@uwa.edu.au

\section{${ }^{5}$ Mark F. RANDOLPH, Ph.D.}

Centre for Offshore Foundation Systems

Oceans Graduate School

University of Western Australia

35 Stirling Highway, Crawley 
53 Perth, WA 6009

54 Australia

55 Email: mark.randolph@uwa.edu.au

56

57

58

59

\section{Susan GOURVENEC, Ph.D.}

60 School of Engineering

61 Faculty of Engineering and Physical Sciences

62 University of Southampton, Southampton, UK

63 Email: Susan.Gourvenec@ southampton.ac.uk

64

No. of words (without abstract and references): 4995

No. of tables:

No. of figures: 


\title{
Numerical investigations of the effect of strain softening on the behaviour of
}

\section{embedded mooring chains}

\author{
Sun, C., Feng, X., Bransby, M.F., Neubecker, S.R., Randolph, M.F., Gourvenec, S.
}

\section{ABSTRACT}

Mooring systems typically consist of an anchor and a mooring line and chain that connect the anchor to the floating infrastructure. When the anchor connection point (the 'padeye') is below the seabed surface, the interaction between the chain and the seabed will affect the amount of load transferred to the anchor and the load angle at the padeye. Reliable methods are needed therefore to assess these aspects in order to determine appropriate anchor design.

Available solutions for the interaction between soil and chain generally ignore any reduction in the undrained shear strength of the soil as it is remoulded under the large strains associated with tensioning of the anchor chain. This is an unconservative assumption for anchor design, hence providing motivation for the study presented here. The system behaviour and the interaction of short chain segments with the seabed have been studied using a coupled Eulerian-Lagrangian (CEL) approach. The findings have led to two new design approaches that encapsulate how remoulding of the soil (which affects sliding resistance more than bearing resistance) affects the chain system response. Calculations using these methods captured the modelled chain system response well. Both the global chain analyses and the proposed design approaches suggest that approximately the entire chain load at the seabed surface (the 'mudline') is likely to be transferred to the anchor padeye, challenging conventional design practice.

Keywords: Anchor chain; catenary mooring; chain-soil interaction; coupled EulerianLagrangian; strain softening; finite element analysis 


\section{INTRODUCTION}

Mooring systems provide the connections to the seabed that keep floating facilities in place and may take various configurations, e.g. catenary, taut or semi-taut and vertical [1]. For a catenary mooring line with load applied horizontally at the seabed, the embedded section of chain forms an 'inverse catenary' between the seabed and the anchor attachment point ('padeye'). The shape of the catenary is such as to maintain equilibrium between the chain tension and the soil resistance. For efficient anchor design the magnitude and inclination of the load at the padeye must be quantified reliably. This is achieved through calculation of the geometric configuration and tension profile of an embedded chain, both of which require quantification of the normal and frictional soil resistances to chain movement along its length. The inverse catenary chain configuration and associated terminology are illustrated in Figure 1.

Existing design approaches for calculating the geometric configuration and tension profile of the embedded section of the chain are summarised in the Appendix, adopting the chain configuration and terminology shown in Figure 1. Traditionally, the soil resistances $Q$ and $F$, normal and parallel to the chain axis, are assumed to be uncoupled and the corresponding ultimate capacities $Q_{u l t}$ and $F_{u l t}$ are assumed to be fully mobilised simultaneously. This does not take account of the resistance reduction due to strain-softening effect of the soil as values for $Q_{u l t}$ and $F_{u l t}$ are generally calculated from the intact (unsoftened) soil strength.

Strain-softening effects on the shear strength, and thus on soil resistance, has been widely investigated in terms of shallow and deep penetration problems [2-5] but limited consideration has been given for the problem of the tensioning process of an embedded anchor chain [6-8]. Remoulding of soil around a chain will lead to less soil resistance along the anchor chain, which will affect the chain profile for a given mudline chain tension value and is likely to lead to a larger proportion of the mudline tension being applied to the anchor at the padeye. This is a 
concern as it is therefore likely to be unconservative to ignore remoulding, despite this being common practice.

\subsection{Scope of the present study}

115 In order to investigate how soil remoulding affects chain performance, this paper extends the

116 Coupled Eulerian-Lagrangian (CEL) finite element approach [9] to explicitly investigate the

117 effect of soil remoulding on both the chain system and the soil resistance to elements of the 118 embedded chain.

119 The paper investigates first the effect of soil sensitivity on the normal and axial resistances by 120 performing a set of segment analyses using Abaqus CEL. Then Abaqus CEL is used to analyse

121 the behaviour of a catenary multi-segment chain system during tensioning for a range of 122 different soil sensitivities. The results from the segment analyses are used to calculate the 123 approximate 'scaled' values of normal resistance and 'friction' coefficient $\mu$. The tensions and 124 geometric configuration of the embedded chain, as two outputs for design, are presented and 125 compared with the analytical predictions by Neubecker and Randolph [10] with the scaled soil 126 resistances. Finally, a method whereby the soil resistance to each chain segment is described 127 by a yield locus is modified for remoulded soil and the results using this method (and the simple 128 scaling method mentioned above) are compared with the CEL results.

\section{FINITE-ELEMENT MODEL}

\subsection{Modelling software and approach}

131 All finite element analyses were carried out with the coupled Eulerian-Lagrangian (CEL)

132 approach provided using the Abaqus software [11]. Furthermore, the approach used and 133 parameters selected (apart from strain softening) were as described in Sun et al. [9]. 134 Consequently, only brief details of common methodology are given here. 


\subsection{Chain geometries}

136 The chain was modelled feasibly as a string of equally spaced, rigid cylindrical segments, 137 connected using 'LINK' connector elements provided as standard in Abaqus (Figure 2a). Three

138 geometric variables - the length $l_{s}$ and the diameter $d_{s}$ of each segment, and the space between 139 adjacent segments, $s_{s}$ - govern the dimensions of the model chain. In the current analyses, $l_{s}$ 140 was taken as $1 \mathrm{~m}$, with $s_{s}$ and $d_{s}$ being $0.1 \mathrm{~m}$ and $0.25 \mathrm{~m}$ respectively.

141 The CEL model was designed to represent a standard $5 d_{b}$ studless chain as shown in Figure $2 \mathrm{a}$.

142 Each link pair of the $5 d_{b}$ studless chain was idealised as one bar segment together with one 143 spacing, i.e, $l_{s}+s_{s}=6 d_{b}=1.1 \mathrm{~m}$, giving $d_{b} \sim 0.18 \mathrm{~m}$ for this model. This relates $d_{s}$ with $d_{b}$ (i.e. $144 d_{s} / d_{b}=0.25 / 0.18$ for this model) for the interpretation of the resistances obtained from the CEL 145 results. Calibration of the model is presented in Sun et al. [9].

146 The global embedded chain system model comprised 49 segments (giving a total length of 53.9 $147 \mathrm{~m}$ ) as shown in Figure 2b. The padeye was set (arbitrarily) to $9 \mathrm{~m}$ below the soil surface and 148 the chain was loaded monotonically and horizontally at the seabed as a catenary mooring during 149 the complete tensioning process. The padeye was fixed (i.e. not allowed to translate vertically 150 or horizontally) to represent an appropriately sized (suction caisson) anchor which would not 151 move significantly under design loads.

\subsection{Soil domain}

The soil was assumed to be fully undrained during the chain tensioning process and

154 consequently total stress analyses were performed. The initial undrained soil strength was

155 assumed to increase linearly with depth $z$, according to $s_{u 0}=2+1.2 z \mathrm{kPa}$, with the effective 156 soil weight being $2.4 \mathrm{kN} / \mathrm{m}^{3}$.

157 The soil was modelled as a linear elastic-perfectly plastic material, obeying the Tresca yield 158 criterion, but extended here to capture the progressive softening of clay [2-6]. The undrained 
The anchor chain was assumed to be weightless and initially 'wished-in-place' in the post-

181 installation configuration ( as in [9]) as shown in Figure $2 b$ with a vertical section fully

shear strength at individual Gauss points was modified immediately prior to re-meshing according to the current accumulated absolute plastic shear strain $\xi$, as presented

$$
S_{u}=\left[\delta_{r e m}+\left(1-\delta_{r e m}\right) \mathrm{e}^{-3 \xi / \xi_{95}}\right] s_{u 0}
$$

The equation models the degradation of soil strength according to an exponential function of cumulative plastic shear strain, $\xi$ ( $\xi_{95}$ represents the value of $\xi$ for $95 \%$ strength degradation), from the intact condition to the fully remoulded ratio, $\delta_{\text {rem }}$ (the inverse of the sensitivity $S_{t}$ ). A user subroutine was implemented into Abaqus to track the evolving soil strength profile. In the analyses, $\xi_{95}$ was taken as 10 , a typical value for clays [3, 4], and $\delta_{\text {rem }}$ ranged from 0.01 to 1 ( $S_{t}$ varies correspondingly from 100 to 1 in order to cover all possible soil sensitivities, including for highly sensitive soils [12]).

The Young's modulus $E$ was taken as $500 s_{u}$ and Poisson's ratio as 0.49 to approximate incompressible soil response for undrained conditions. The regular mesh comprised 8-noded linear brick elements with reduced integration ('EC3D8R' in the Abaqus element library). A central fine mesh zone (minimum mesh size $L_{e}=0.35 d_{s}$ ) was used in the area close to the predicted chain trajectory during the tensioning process. This overall mesh resulted in each single chain system analysis taking approximately 350 hours to run on a fast server and, even with this mesh, this did not result in a fully convergent solution (see [9] for more details). This was considered when interpreting the results of the analyses as described later.

\subsection{CEL model setup}

The global view of the CEL model is present in Figure $2 b$ together with the detailed chain model.

$$
\text { embedded and attached to a fixed point, i.e. the padeye of a suction anchor, and a horizontal }
$$


section laid on the seabed. Analyses were started at the 'wished-in-place' configuration to reduce computational time because the loaded chain configuration involves significant movement of the chain away from its installed position so that any soil that is influenced by the chain installation process is far enough away not to affect the later chain-soil interaction. Subsequently, the motion of the dragging point was activated by applying a constant horizontal velocity $v_{d}$, forcing the chain to cut gradually through the soil until the final padeye inclination angle $\theta_{a}$ reached $35^{\circ}$ to the horizontal. The local coefficient of friction of the chain-soil interface was selected as 0.5 times the normal force using the 'penalty' contact option in Abaqus CEL. Using this value, the frictional resistance to purely axial movement of chain at the deep embedment conditions was governed by the shearing of the peripheral soil instead of interface sliding, with the results essentially unaffected by the specific value (of 0.5 ) selected. Note that the frictional interface allows gapping behind the advancing chain once the normal pressure becomes tensile.

\section{CHAIN SEGMENT ANALYSES: SOIL RESISTANCES WITH DIFFERENT SOIL} SENSITIVITIES

Before conducting the analyses of the entire chain system, the pure normal $(Q)$ and frictional $(F)$ resistance response (and so the ratio $F / Q$ ) as a function of $S_{t}$ was investigated numerically using Abaqus CEL. One set of analyses displaced a buried multi-segment section of chain vertically (i.e. normal to its axis) until the residual normal resistance $\left(Q_{\text {res }}\right)$ was mobilised for a range of soil sensitivities $S_{t}$. The analyses were then repeated for axial chain movements to determine $F_{\text {res. }}$

The analyses were conducted on the straight, neutrally-buoyant, seven-segment section of chain (Figure 3(a)) embedded horizontally at a depth of $18 d_{s}$ (at $4.5 \mathrm{~m}$ where $s_{u 0}=7.4 \mathrm{kPa}$ ), to get 'deep' failure conditions (i.e. localised flow-around of the soil and a mechanism that was 
independent of the distance to the soil surface). The CEL setup details, including the soil properties, chain size, interface properties, boundaries, mesh refinement and simulation velocities, are consistent with those adopted in the global embedded chain model. End effects

were avoided by excluding the outer two segments when calculating the length-averaged soil resistances. The segment analyses used the same mesh density and velocity as in the system analyses so that the relationships developed would be consistent.

The normal and frictional resistance factors $N_{b}=Q / d_{b} s_{u 0}$ and $N_{s}=F / d_{b} s_{u 0}$, and the

214 corresponding quantities normalised using the (numerical) 'chain' diameter, $d_{s}$, are plotted against chain movements in Figure 3(b) and (c) for soil sensitivities $S_{t}=1,2,5,10$ and 100, where $Q$ and $F$ are respectively the normal and frictional soil resistance forces on the five central segments of the chain per unit length (with units $\mathrm{kN} / \mathrm{m}$ ) and $s_{u 0}$ is the intact undrained strength at the current depth of the chain element centroid. The figures show that approximately two to three diameters of chain movement is required to mobilise a steady-state residual resistance for $S_{t}>1$ and the selected value of $\xi_{95}$ of 10 . Note that this is considerably less movement than experienced by a large majority of the chain elements during tensioning in the full analysis presented later.

223 For the non-softening soil $\left(S_{t}=1\right)$, the normalised ultimate normal and frictional resistances for the embedded chain are defined as $N_{b, u l t}$ and $N_{s, u l t}$ with $N_{b, u l t}=Q_{u l t} / d_{b} S_{u 0}=19$ and $N_{s, u l t}=F_{u l t} / d_{b} S_{u 0}$ $=6.5$ (benchmarked by 19 and 8 from the Degenkamp and Dutta [13] recommendation and

226 adopted for the estimation of the Neubecker and Randolph solutions). Accordingly, the 227 coefficient of friction $\mu_{p}=N_{s, u l t} / N_{b, u l t}=0.34$.

228 For the softening soil (with $S_{t}>1$ ), the steady-state normal and frictional resistance factors $N_{b, r e s}$ and $N_{s, \text { res }}$ were calculated based on deduced residual values of soil resistance $\left(Q_{r e s}\right.$ and $\left.F_{r e s}\right)$ from the monotonic resistance curves shown on Figure 3(b) and (c). The selected values 
normalised by the value of resistance for non-softening (i.e. $S_{t}=1$ ) soil are shown as dots on

232

233

Figure 4.

The residual resistance ratios $Q_{r e s} / Q_{u l t}$ and $F_{r e s} / F_{u l t}$ normal and parallel to the chain axis may be expressed as linear functions of the remoulded strength ratio $\delta_{\text {rem }}$.

$$
\frac{Q_{r e s}}{Q_{u l t}}=\frac{N_{b, r e s}}{N_{b, u l t}}=0.4 \delta_{r e m}+0.6
$$

These functions are plotted in Figure 4. The consequent residual frictional ratio is therefore expressed as:

$$
\frac{F_{r e s}}{F_{\text {ult }}}=\frac{N_{s, r e s}}{N_{s, u l t}}=0.8 \delta_{\text {rem }}+0.2
$$

The fitted equations are used to interpret the CEL chain system analysis results and their applicability for design is discussed later.

Supplementary data using a finer mesh $\left(L_{e}=0.0875 d_{s}\right)$ to analyse the behaviour of two segments, as a link pair, are also plotted for the validation of the functions. More detail concerning the selection of the residual resistance factors (and their similarity to the behaviour of T-bar penetrometers) is presented at the end of the paper.

\section{CHAIN SYSTEM ANALYSES: RESULTS}

Figure 5 shows the padeye angle - tension relationships obtained from the CEL analyses for soil sensitivities $S_{t}=1,2,5,10,100$. The tensions develop linearly initially, but with a gradually increasing rate as the chain angle decreases, i.e. as the chain becomes taut. For a given chain tension, the padeye angle is smaller (i.e. the chain is 'flatter') with increasing sensitivity because the chain penetrates further through the remoulding soil, as shown on Figure 6. 

274 along the chain.

Analytical predictions by Neubecker and Randolph [10] for the relationship between the padeye tension $\left(T_{a}\right)$ versus the padeye chain angle $\left(\theta_{a}\right)$ are also shown on Figure 5 . These are based on residual values of $Q_{\text {res }}$ and $\mu_{\text {res }}$ in Equation A-4 [10], for the given soil sensitivity, and show good agreement with the CEL data. Although the true mobilised friction coefficient along the chain is much less than the nominal value $\mu_{\text {res }}$ (see later discussion), this does not compromise the level of agreement, reflecting that the analytical solution is essentially independent of $\mu$ after adopting the small angle assumption (Equation A-5) [9].

This is illustrated further in Figure 7, which compares the configurations of the embedded chain obtained from the CEL analyses with soil sensitivities $S_{t}=1,2,5,10,100$ for two chain inclination angles at the padeye $\left(\theta_{a}=60^{\circ}\right.$ and $\left.35^{\circ}\right)$ during the tensioning process. The configurations are presented in terms of the chain-angle variation $\left(\theta_{a}^{2}-\theta^{2}\right) / 2$ against the normalised embedment depth $z / z_{a}$, conforming to the simplified analytical solution of Equation A-5 (Neubecker and Randolph [10]). The CEL results for different soil sensitivities fall within a narrow band, reflecting that the chain geometry is relatively insensitive to $S_{t}$ for a given chain padeye angle. Furthermore, the agreement between the CEL results and the analytical predictions derived from Eq. (A-4) with $Q=19 d_{b} s_{u}$ and $\mu=\mu_{p}=0.34$ demonstrates that the Neubecker and Randolph solution can still be used to estimate the chain configuration (for a given $\theta_{a}$ ) even in softening clay.

The results of CEL analyses of the tension ratio $T_{a} / T_{m}$ are shown on Figure 8 as a function of the decreasing padeye angle for varying soil sensitivities $S_{t}=1,2,5,10,100$. The tension ratio increases with decreasing $\theta_{a}$, as would be expected. Also, as sensitivity becomes higher, the tension ratios increase towards unity, reflecting the reduction in frictional resistance mobilised 
Sun et al. [9] showed that the 'operative' coefficient of friction in non-softening soil was much lower than the theoretical value of $\mu=0.34$, and that a value of $\mu_{o p}=0.07$ was needed in order to match CEL data using the Neubecker and Randolph relationship of Equation A-3. The CELcalculated tension ratio values are compared with analytical predictions in Figure 8. In the analytical predictions, the 'operative' coefficient of friction $\mu$ values used in Equation A-3 were selected as the friction coefficient $\mu_{o p}$, res for the residual state of soil remoulding by scaling the non-softening $\left(S_{t}=1\right)$ value of $\mu_{o p}=0.07$ for each different soil sensitivity using the results of the segment analysis, i.e. Equation 4. This simple method by scaling $\mu_{o p}$ to $\mu_{o p}$, res gives relatively good agreement with the CEL results for the conditions examined in Figure 8.

\section{DESIGN METHOD USING YIELD LOCI}

The above empirical design approach of scaling normal resistance with $S_{t}$ to get the chain shape (for a given anchor tension) and scaling $\mu$ as another function of $S_{t}$ (to calculate the chain tension), both based on results for pure normal and axial displacement, appears to give reasonable results. However, although this allows approximation of the system behaviour, to account for changes to the friction/tension ratio along the chain a modified version of the yield locus based approach proposed by Sun et al. [9] is required. The yield loci (and associated plastic potential) for embedded chain segments is used to calculate the resistance ratio $F / Q$ during failure from the kinematics (i.e. the plastic displacement ratio) of each element along the chain. This section presents this method, modified to allow for soil remoulding, and then shows system analysis results using this method compared with the scaling approach and CEL results.

\subsection{Calculating the yield locus from segment analyses}

To develop yield loci accounting for remoulding of soil, a suite of monotonic displacementcontrolled probes (each at a different displacement angle $\omega$ to the normal of the chain axis) 
were conducted on the seven-segment section of chain (centroid depth $=18 d_{s}\left(4.5 \mathrm{~m}, s_{u 0}=7.4\right.$

$\mathrm{kPa}$ )). This was carried out for a typical value of soil sensitivity $S_{t}=5$ (representative for clay/carbonate silt) to examine the behaviour in detail.

302

The resulting interaction diagrams are shown in terms of normalised normal and frictional resistances $N_{b}$ and $N_{s}$ in Figure 9. A yield locus in the form of a generalised ellipse is proposed to describe residual conditions:

$$
\left(\frac{N_{b}}{N_{b, \text { res }}}\right)^{m}+\left(\frac{N_{s}}{N_{s, \text { res }}}\right)^{n}=1
$$

where $N_{b}$, res and $N_{s, \text { res }}$ are the calculated residual resistances for pure normal and axial movement respectively and $m$ and $n$ are fitting parameters. The locus shown uses values of $N_{b}$, res and $N_{s, \text { res }}$ based on the linear residual resistance ratio-strength ratio relationships (Figure 4) for $S_{t}=5 ; m$ and $n$ were selected as 2.0 and 2.3 to be identical to the values recommended in non-softening soil conditions [9] for simplicity. The agreement of the probe tests with the yield locus described by Equation 5 suggests that the adopted parameters are acceptable for engineering design purposes. Even better agreement could be obtained by modifying the values of $m$ and $n$ for the remoulded case specifically, but doing so would have the disadvantage of having to ascertain new $m$ and $n$ values for each new residual yield locus without a significant increase in accuracy.

Since reduction of the normal and frictional resistances to residual values does not involve the same magnitude of relative displacement of the chain (frictional resistance being remoulded more easily), the shrunken locus is relatively flat in the normal resistance direction compared with the yield locus for non-remoulding $\left(S_{t}=1\right)$ soil. Interestingly, for the soil sensitivity selected $\left(S_{t}=5\right)$, none of the $Q-F$ load paths reaches the non-softening $\left(S_{t}=1\right)$ locus except the 
two close to the purely frictional loading condition, since partial remoulding occurs as that locus is approached.

\subsection{Examination of chain segment behaviour during system analyses}

324 Figure 10 plots the evolution of the normalised normal and frictional soil resistances, $Q / Q_{u l t}$ and $F / F_{\text {ult }}$ for two representative chain segments (identified as ' $\# 13$ ' and ' $\# 25$ ' on Figure 2) during tensioning from the system CEL analysis for $S_{t}=5$. The load components are compared with the yield loci of the chain for the softening $\left(S_{t}=5\right)$ and non-softening $\left(S_{t}=1\right)$ cases. Both segments initially lie on the seabed (where the yield locus is smaller than for the 'deep' condition for which the yield loci shown correspond), and penetrate deeper as the chain cuts progressively into the soil. As $T_{m}$ increases (and $\theta_{a}$ reduces), the $Q-F$ loading condition of the chain segments moves towards a residual bearing condition close to the remoulded yield locus, due to local remoulding of the soil. For small values of chain angle (i.e. large values of $T_{m}$ ), the resistance approaches the pure normal bearing condition $\left(Q \sim Q_{\mathrm{res}}, F \sim 0\right)$ implying that the mobilised operative $F / Q$ ratios (i.e. $\mu$ in analytical equations) approach zero. The $Q-F$ data lie close to the residual locus, especially for the deeper chain segment, implying that the residual locus does indeed capture the soil failure conditions following strain-softening.

\subsection{Calculation of the equivalent friction coefficient}

338 The residual yield locus may be used to calculate an equivalent frictional coefficient of the

339 embedded chain, considering strain-softening, based on the analytical method proposed in Sun

340 et al. [9]. The local equivalent coefficient of friction $\mu_{l e}$ can be determined by substituting the 341 residual resistance factors $N_{s, \text { res }}$ and $N_{b}$, res for the corresponding original ultimate values for 342 given soil sensitivity $\left(S_{t}=5\right.$ in this case):

$$
\mu_{l e}=\left[\frac{m}{n}\left(\frac{N_{s, \mathrm{res}}}{N_{b, \mathrm{res}}}\right)^{n} \frac{\Delta u_{t}}{\Delta u_{n}}\right]^{1 /(n-1)}
$$


The incremental (plastic) displacement ratio, $\Delta u_{t} / \Delta u_{n}(\tan \omega)$ defined locally at each chain segment, can be evaluated by estimation of the incremental trajectory of chain using the Neubecker and Randolph solution [9].

The results at each segment of the chain can be integrated to calculate the average representative $\mu$ value and therefore calculate $T_{a} / T_{m}$ at each step of chain tensioning (as proposed by Sun et al. [9]). The predictions of $T_{a} / T_{m}$ calculated by Equation A-3 using the yield locus aproach $\left(\mu_{o p, \text { res }}^{\text {mod }}\right)$ and by taking a constant scaled $\mu_{o p}$, res of 0.037 by Equation 4 as illustrated on Figure 8) are compared with the CEL results for $S_{t}=5$ during the tensioning process in Figure 11 . The tension ratio calculated using the yield locus approach shows an increase from under 0.97 when $\theta_{a}=$ $75^{\circ}$ to just over 0.98 when $\theta_{a}=35^{\circ}$. Despite fluctuations of the CEL results and a relatively small range of the changing $T_{a} / T_{m}$, the values derived using the yield locus approach show better agreement with the numerical results than from using the $\mu$-scaling approach with $\mu_{o p}$, res $=$ 0.037, particularly as the chain becomes taut.

\section{IMPLICATIONS FOR DESIGN}

The most significant outcome from the study presented here is the extremely low reduction in tension between mudline and padeye compared with what is generally assumed in anchor design. Even in non-softening soil, the operative friction is 0.07 , only $20 \%$ of the nominal

361 friction value of 0.34 . For a strain-softening soil with $S_{t}=5$, which is typical of marine deposits,

362 the operative friction will reduce further to approximately 0.037 . Cyclic motions of the chain 363 would give even lower values of operative friction. This is significant for anchor design because 364 it suggests that more of the mooring load will be transferred to the anchor than previously 365 thought, and implies that previous design methods were unconservative.

366 The agreement between the CEL results and the two possible design methods in Figure 11 367 demonstrates the feasibility of either proposed method for the calculation of the equivalent 
frictional coefficient of the embedded chain for strain-softening soils in undrained conditions

(albeit some of the numbers in the equations may change with varying soil, chain and anchor conditions).

Both methods require knowledge of how the normal $(Q)$ and frictional $(F)$ resistances are affected by soil sensitivity. For the CEL system analysis comparisons, these relationships were obtained by performing separate segment analyses using Abaqus CEL (see Figure 4). However, the analyses performed were necessarily limited in their use of mesh size (because of the computational cost of the system analyses) and so the relationships produced (e.g. Eqs. (2) and (3)) cannot be used directly in design. This is discussed below with further segment analyses conducted using Abaqus CEL for bearing and sliding resistance in turn.

\subsection{Bearing resistance $\left(Q_{\text {res }}\right)$}

379 In order to provide recommendations for design related to how the normal chain resistance $\left(Q_{\text {res }}\right)$

380 varies with sensitivity, additional segment analyses were carried out using CEL analyses of the 381 link geometry with finer meshes (with element length, $L_{e}=0.0875 d_{s}$ ) and the results were 382 compared with the analagous problem of a T-bar penetrating sensitive soils $[12,14]$.

383 The additional information is shown on Figure 12 including an empirical equation fitted to 384 scattered T-bar field testing results [12] and from two-dimensional numerical analyses of a T385 bar incorporating both strain-softening and rate effects [14]. In addition, a dashed line 386 representing the simplification that all soil in front of the chain is intact (i.e. has strength $s_{u 0}$ ) 387 and all soil behind is fully remoulded (i.e. has strength $s_{u 0} / S_{t}=\delta_{\text {rem }} s_{u 0}$ ) is included. This 388 approach has been used in practice [15] to approximate bearing resistance of embedded 389 foundation or anchor elements during large deformation events.

390 When selecting a design line it should be realised that the geometry studied in CEL (and that 391 of a T-bar) is not a collection of chain links (as in a real chain) and so the relationship for a real 
chain may be slightly different. However, the numerical results on Figure 12 suggest that the intuitive engineering approximation with $Q_{r e s} / Q_{u l t}$ equal to $0.5+0.5 / S_{t}$ provides a sufficient 394 approach.

\subsection{Axial resistance $\left(F_{r e s}\right)$}

Additional CEL chain segment analyses were also conducted using CEL with finer mesh sizes to investigate further the relationship between axial resistance $F_{\text {res }}$ and sensitivity. The additional data shown on Figure 4 for the finer mesh analyses do not invalidate the previouslyproposed Equation 3. However, as discussed above, the simplification of the chain geometry from a collection of links to a bar sections (with links) means that the results may not be truly representative of chain behaviour. This may be particularly the case for axial chain movement where the ratio of soil bearing (around the two ends of the bars) versus sliding failure (along the link bars) will not be recreated. Consequently, the relationship proposed here is tentative and warrants further study.

\section{CONCLUSIONS}

Large deformation finite element analyses were conducted to investigate the effect of strain softening on the normal and frictional resistances of embedded chain sections, and the global monotonic tensioning behaviour of an embedded chain. The coupled Eulerian-Lagrangian (CEL) approach was used with a strain-softening soil model incorporated. A linearly increasing relationship between residual resistance ratio and the remoulded soil strength ratio was found first and then examined by comparing the numerical results featuring different mesh densities with the empirical predictions. The CEL results of the tension at the padeye with increasing soil sensitivity can be replicated by scaling the analytical predictions by Neubecker and Randolph [10] down by the residual resistance ratio according to a simplified linear residual resistancesoil strength relationship. The CEL results for the geometry of the embedded chain agree well 
with the Neubecker and Randolph analytical solutions for non-softening soil, due to compensating effects whereby the reduced normal resistance on each chain segment is balanced by the reduced padeye tension required to achieve a given chain angle at the padeye. The average operative friction of the embedded chain also shows a reduction in accordance with softening of soil. The reductions in steady-state normal and frictional chain resistance can be represented by a shrunken yield locus for the deeply embedded segments. The calculation method proposed by Sun et al. [9] may then be used to simulate the global chain response during tensioning. Overall, the most significant effect of soil remoulding is that the reduction in chain tension between mudline and anchor padeye becomes extremely small, equivalent to a chain friction ratio $\mu$ of less than 0.05 for typical soil sensitivities in the range 3 to 5 .

\section{ACKNOWLEDGEMENTS}

This work forms part of the activities of the Centre for Offshore Foundation Systems.

428 Established in 1997 under the Australian Research Council's Special Research Centres Program 429 and currently supported as a node of the Australian Research Council's Centre of Excellence for Geotechnical Science and Engineering (ARC grant CE110001009), and through the Fugro

431 Chair in Geotechnics, the Lloyd's Register Foundation Chair and Centre of Excellence in 432 Offshore Foundations and the Shell EMI Chair in Offshore Engineering. The first author is 433 supported with an Australian Government Research Training Program Scholarship and a Fugro 434 PhD Scholarship, the second author is supported by the National Natural Science Foundation of China (No. 51890915) and the third author is supported as the Fugro Chair in Geotechnics.

436 All the support above is gratefully acknowledged. 


\section{REFERENCES}

438 [1] M. F. Randolph, S. Gourvenec. Offshore geotechnical engineering: CRC Press, 2011.

439 [2] I. Einav, M. F. Randolph. Combining upper bound and strain path methods for evaluating 440 penetration resistance. Int. J. Numer. Methods Eng. 63 (2005) 1991-2016.

441 [3] H. Zhou, M. F. Randolph. Computational techniques and shear band development for 442 cylindrical and spherical penetrometers in strain-softening clay. Int. J. Geomech. 7 (2007) $443 \quad 287-295$.

444 [4] H. Zhou, M. F. Randolph. Numerical investigations into cycling of full-flow 445 penetrometers in soft clay. Géotechnique. 59 (2009) 801-812.

446 [5] S. Chatterjee, M. F. Randolph, D. J. White. The effects of penetration rate and strain 447 softening on the vertical penetration resistance of seabed pipelines. Géotechnique. 62 (2012) $448 \quad 573-582$.

449 [6] Y. Kim, M. S. Hossain, D. Wang. Dynamically Installed Anchors: Performance of 450 embedded mooring chain profile in clay. In: Meyer, editor. Frontiers in Offshore Geotechnics 451 III. London: Taylor \& Francis Group; 2015. p. 881-886.

452 [7] Y. Zhao, H. Liu. Numerical implementation of the installation/mooring line and application to analyzing comprehensive anchor behaviors. Appl. Ocean Res. 54 (2016) 101454114.

[8] Y. Zhao, H. Liu, P. Li. An efficient approach to incorporate anchor line effects into the 456 coupled Eulerian-Lagrangian analysis of comprehensive anchor behaviors. Appl. Ocean Res. $457 \quad 59(2016) 201-215$.

458 [9] C. Sun, X. Feng, S. R. Neubecker, M. F. Randolph, M. F. Bransby, S. Gourvenec.

459 Numerical study of mobilized friction along embedded catenary mooring chains. J. Geotech. 460 Geoenviron. Eng. (accepted) (2019a).

461 [10] S. R. Neubecker, M. F. Randolph. Profile and frictional capacity of embedded anchor 462 chains. J.Geotechn. Eng. 121 (1995) 797-803. 
[11] Dassault Systèmes. ABAQUS 6.14 Analysis User's Manual. Providence, RI, USA.:

464 Simulia Corp, 2014.

465
[12] J. T. DeJong, N. J. Yafrate, D. J. DeGroot. Evaluation of Undrained Shear Strength

Using Full-Flow Penetrometers. J. Geotech. Geoenviron. Eng. 137 (2011) 14-26.

[13] G. Degenkamp, A. Dutta. Soil resistances to embedded anchor chain in soft clay.

J.Geotechn. Eng. 115 (1989) 1420-1438.

[14] S. Pinkert, A. Klar. Discussion of "Evaluation of Undrained Shear Strength Using Full-

Flow Penetrometers" by Jason T. DeJong, Nicholas J. Yafrate, and Don J. DeGroot. J.

Geotech. Geoenviron. Eng. 138 (2012) 763-765.

[15] M. P. O’Neill, S. R. Neubecker, C. T. Erbrich. Installation and in-place assessment of drag anchors in carbonate soil. Frontiers in Offshore Geotechnics II: CRC Press; 2010. p. 765-770.

[16] L. C. Reese. A design method for an anchor pile in a mooring system. Offshore Technology Conference, Offshore Technology Conference, 1973.

[17] J. A. Gault, W. R. Cox. Method for predicting geometry and load distribution in an anchor chain from a single point mooring buoy to a buried anchorage. Offshore Technology Conference, Offshore Technology Conference, 1974.

[18] V. Vivatrat, P. J. Valent, A. A. Ponterio. The influence of chain friction on anchor pile design. Offshore Technology Conference, Offshore Technology Conference, 1982.

[19] A. Dutta, G. Degenkamp. Behaviour of embedded mooring chains in clay during chain tensioning. Offshore Technology Conference, Offshore Technology Conference, 1989. 


\section{APPENDIX - EXISTING DESIGN RELATIONSHIPS}

486

487

488

$$
\frac{T_{a}}{1+\mu^{2}}\left[e^{\mu\left(\theta_{a}-\theta\right)}(\cos \theta+\mu \sin \theta)\right]_{\theta}^{\theta_{a}}=\int_{z}^{z_{a}} Q d z
$$

Behaviour of the embedded chain may be obtained by integrating the governing equilibrium equations

$$
\frac{d T}{d s}=F+w_{c} \sin \theta
$$

from one end of the chain to the other $[13,16-19]$. Here $T$ is the tension in the chain acting over the incremental chain length $d s, \theta$ the chain angle to the horizontal, $w_{c}$ the submerged weight of chain per unit length, and $Q$ and $F$ respectively the normal and frictional soil resistances per unit length in the directions perpendicular and parallel to the chain axis. The boundary conditions are $T_{a}$ and $\theta_{a}$ at the padeye at depth $z_{a}$, leading to tension $T_{m}$ and $\theta_{m}$ (taken as zero here) at mudline.

Closed-form solution of the differential equations (Eqs. (A-1) and (A-2)) is possible by neglecting the weight of the chain, producing the tension profile [10]

$$
\frac{T}{T_{a}}=e^{\mu\left(\theta_{a}-\theta\right)}
$$

with the chain friction coefficient $\mu$ defined as the ratio $F / Q$.

The corresponding variation of the chain angle is then

which may be simplified where the chain angle is small to 


$$
\frac{T_{a}}{2}\left(\theta_{a}^{2}-\theta^{2}\right)=\int_{z}^{z_{a}} Q d z
$$

504

505

\section{NOMENCLATURE}

$506 \quad d_{b} \quad$ diameter of the link bar for the real chain

$507 d_{s} \quad$ diameter of the chain segment in the CEL model

$508 \quad F \quad$ frictional soil resistance

$509 \quad F_{\text {res }}$ residual frictional soil resistance

$510 \quad F_{\text {ult }} \quad$ ultimate frictional soil resistance

$511 L_{e} \quad$ minimum size of the soil elements

$512 \quad l_{s} \quad$ length of the chain segment in the CEL model

$513 m$ fitting shape factor for the yield locus

$514 \quad n \quad$ fitting shape factor for the yield locus

$515 \quad N_{b} \quad$ normal soil resistance factor

$516 N_{b, \text { res }}$ residual normal soil resistance factor

$517 \quad N_{b, \text { ult }}$ ultimate normal soil resistance factor

$518 \quad N_{s} \quad$ frictional soil resistance factor

$519 N_{s, \text { res }}$ residual frictional soil resistance factor

$520 N_{s, \text { ult }}$ ultimate frictional soil resistance factor

$521 \quad Q \quad$ normal soil resistance 
$522 Q_{\text {res }}$ residual normal soil resistance

$523 Q_{\text {ult }} \quad$ ultimate normal soil resistance

$524 S_{s} \quad$ space between adjacent chain segments in the CEL model

$525 \quad S_{t} \quad$ soil sensitivity

$526 s_{u} \quad$ instantaneous undrained soil shear strength

$527 \quad s_{u 0} \quad$ initial undrained soil shear strength

$528 \quad T \quad$ chain tension

$529 \quad T_{a} \quad$ chain tension at the padeye

$530 \quad T_{m} \quad$ chain tension at the mudline

$531 w_{c} \quad$ submerged weight of chain per unit length

$532 \quad z \quad$ embedment depth

$533 \quad z a \quad$ anchor padeye depth

$534 \delta_{\text {rem }} \quad$ remoulded soil strength ratio (the inverse of the soil sensitivity $S_{t}$ )

$535 \Delta u_{t} / \Delta u_{n}(\tan \omega) \quad$ incremental (plastic) displacement ratio

$536 \theta \quad$ chain angle

$537 \quad \theta_{a} \quad$ chain angle at the padeye

$538 \quad \theta_{m} \quad$ chain angle at the mudline

$539 \mu \quad$ chain friction coefficient (as used for calculation)

$540 \quad \mu_{l e} \quad$ local equivalent friction coefficient (calculated by the yield-locus method) 
$541 \mu_{o p} \quad$ operative friction coefficient

$542 \mu_{o p, r e s}$ residual operative friction coefficient (calculated by scaling $\mu_{o p}$ )

$543 \mu_{p} \quad$ equivalent friction coefficient of chain adopted in the current design practice $(=$ $\left.544 \quad N_{s, u l t} / N_{b, u l t}\right)$

$545 \mu_{\text {res }} \quad$ residual friction coefficient (calculated by scaling $\mu_{p}$ )

$546 \quad \xi \quad$ cumulative plastic shear strain

$547 \quad \xi_{95} \quad$ value of cumulative plastic shear strain for $95 \%$ strength degradation 
Figure captions

551 Figure 1. Schematic of geometric configuration and tension profile of an embedded chain and

552 the mechanical equilibrium of a chain element

553 Figure 2. CEL modelling of the embedded chain

554 Figure 3. CEL model for chain segment analyses and the soil resistances with different soil 555 sensitivities

556 Figure 4. Residual capacity ratios of the embedded chain model

557 Figure 5. Comparison of tension-padeye angle relationships with different soil sensitivities

558 Figure 6. Chain profiles for different soil sensitivities at two mudline tensions

559 Figure 7. Comparison of the configurations of the embedded chain for selected chain

560 inclination angles

561 Figure 8. Comparison of tension ratio-padeye angle relationships with different soil

562 sensitivities

563 Figure 9. Probe testing results for $S_{t}=5$

564 Figure 10. Evolution of the soil resistances to representative chain segments to tensioning $\left(S_{t}\right.$ $565=5$ )

566 Figure 11. Tension ratio $T_{a} / T_{m}$ calculated with modified operative frictional coefficient $\left(S_{t}=\right.$ $567 \quad 5)$

568 Figure 12. Comparison of resistance factors of a bar for design implications 


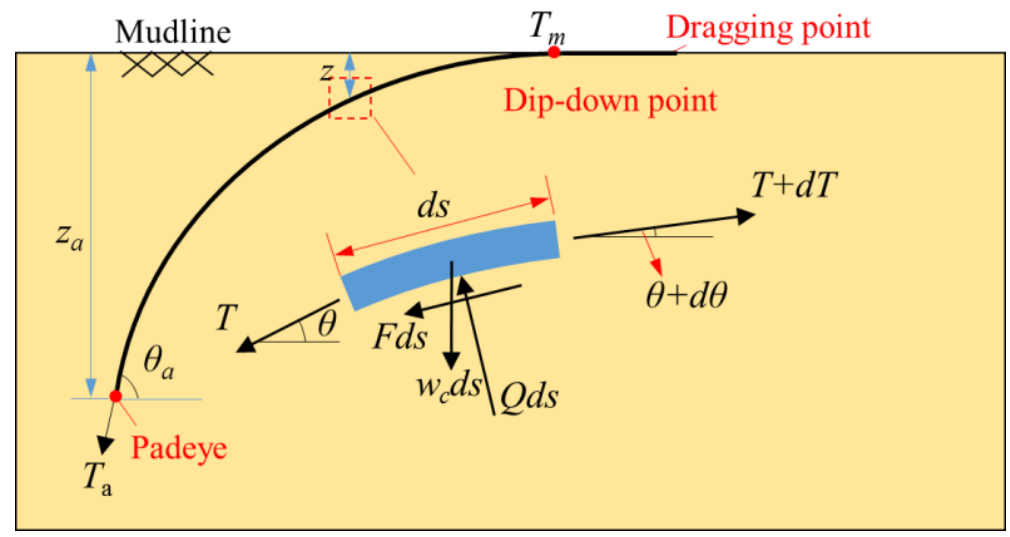

571 Figure 1. Schematic of geometric configuration and tension profile of an embedded chain and the mechanical equilibrium of a chain element 


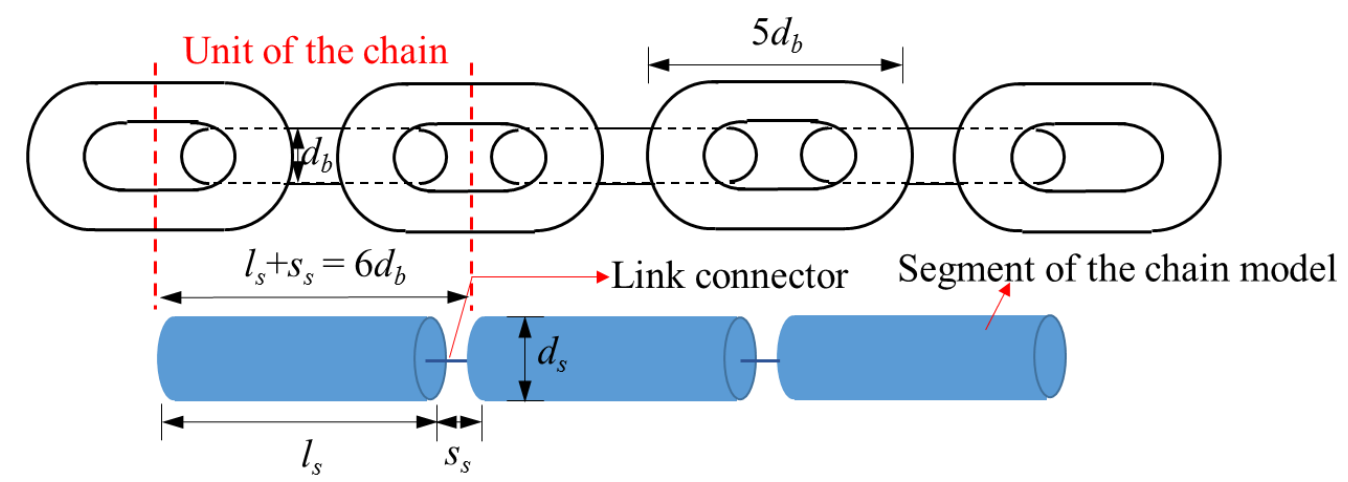

(a) Chain model corresponding to a $5 d_{b}$ studless chain

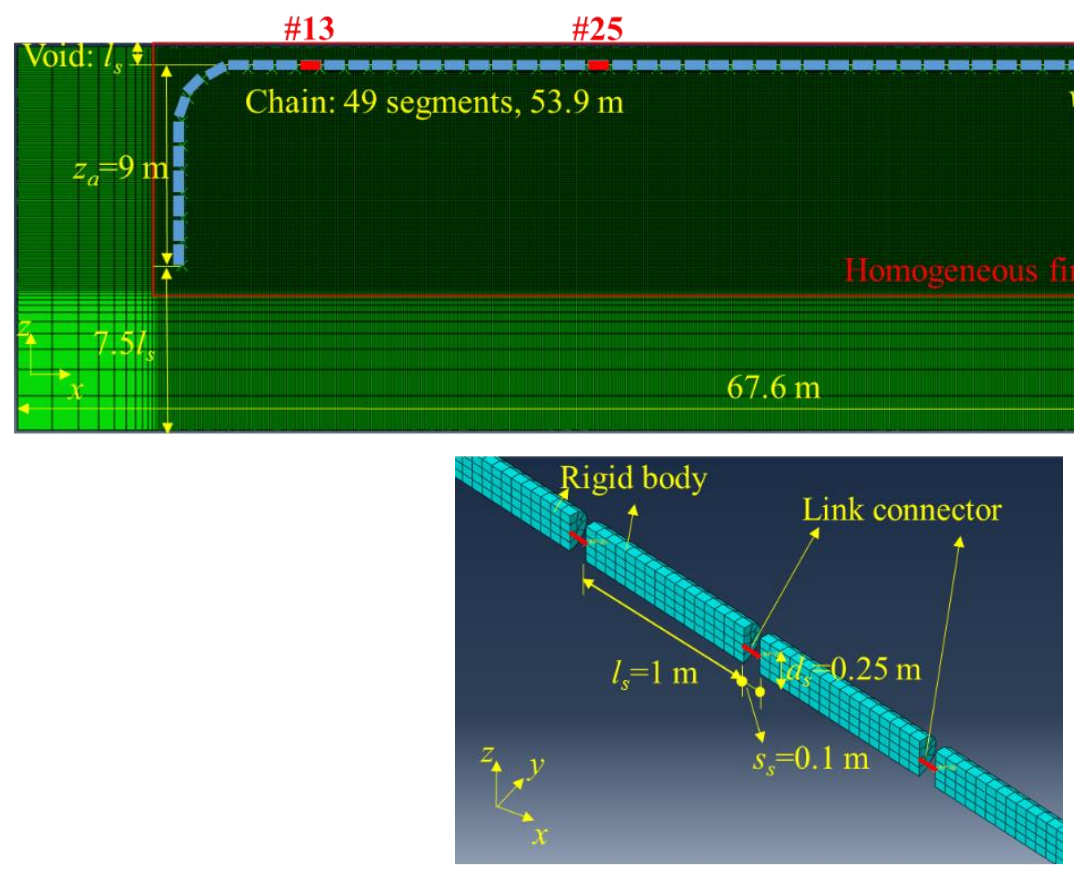

576 (b) FE model setup

Figure 2. CEL modelling of the embedded chain 


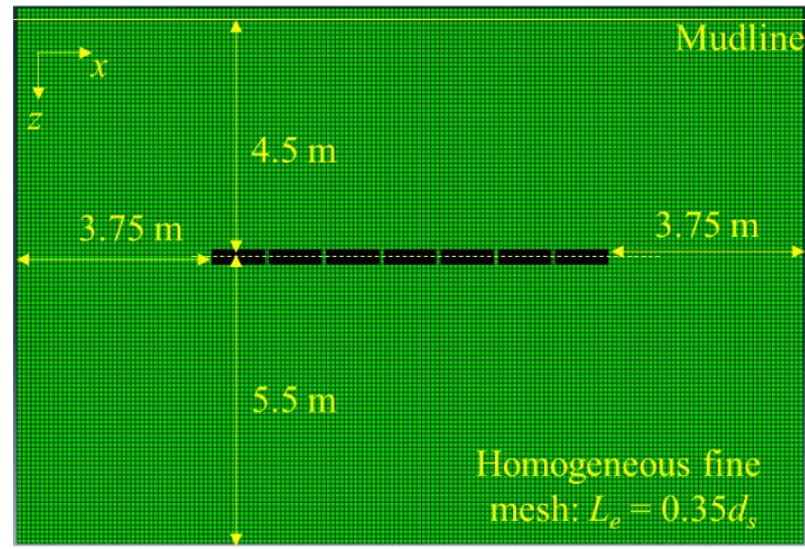

(a) CEL model for the chain segment analyses

581

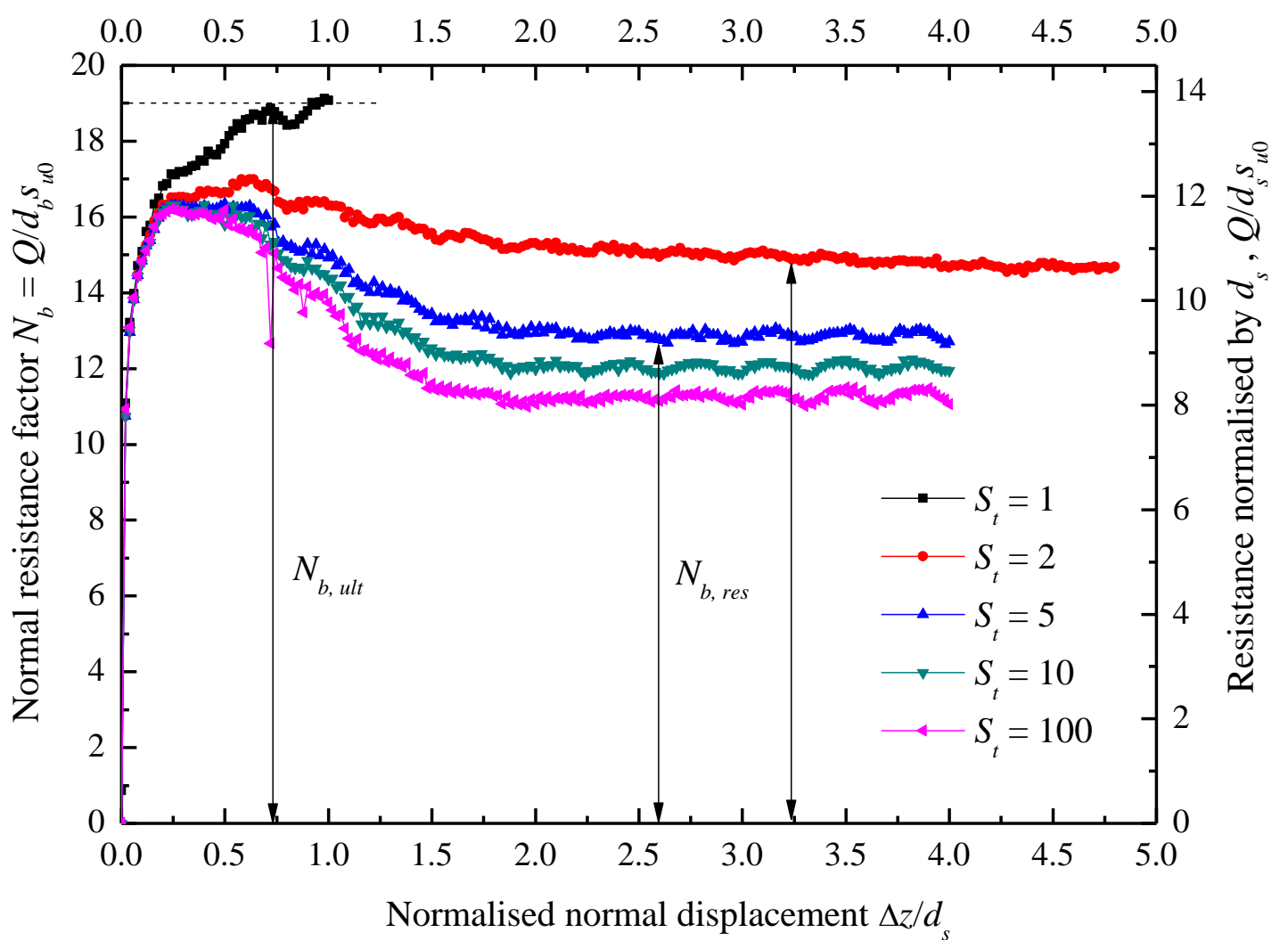

(b) Normal resistance 


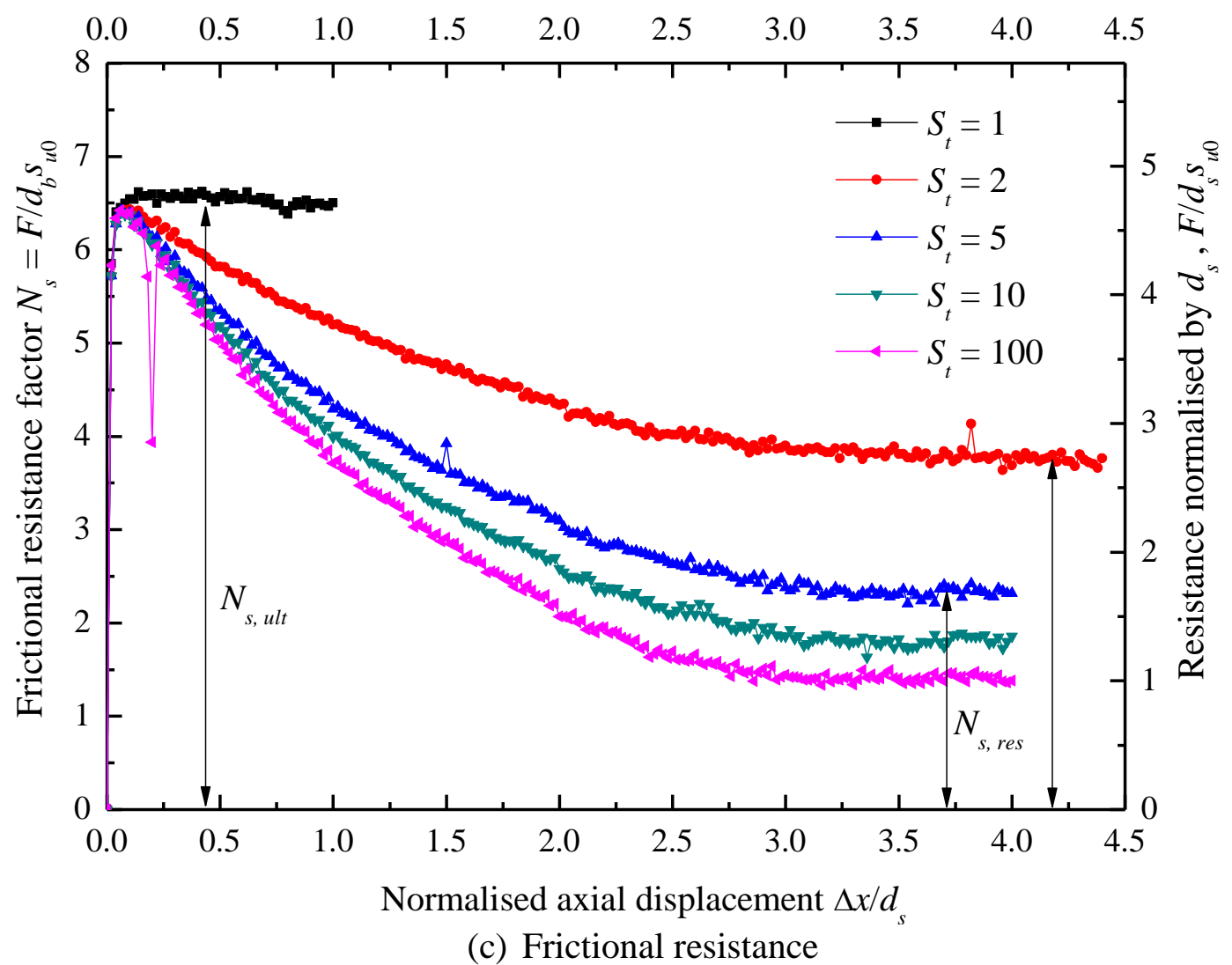

(c) Frictional resistance

Figure 3. CEL model for chain segment analyses and the soil resistances with different soil 


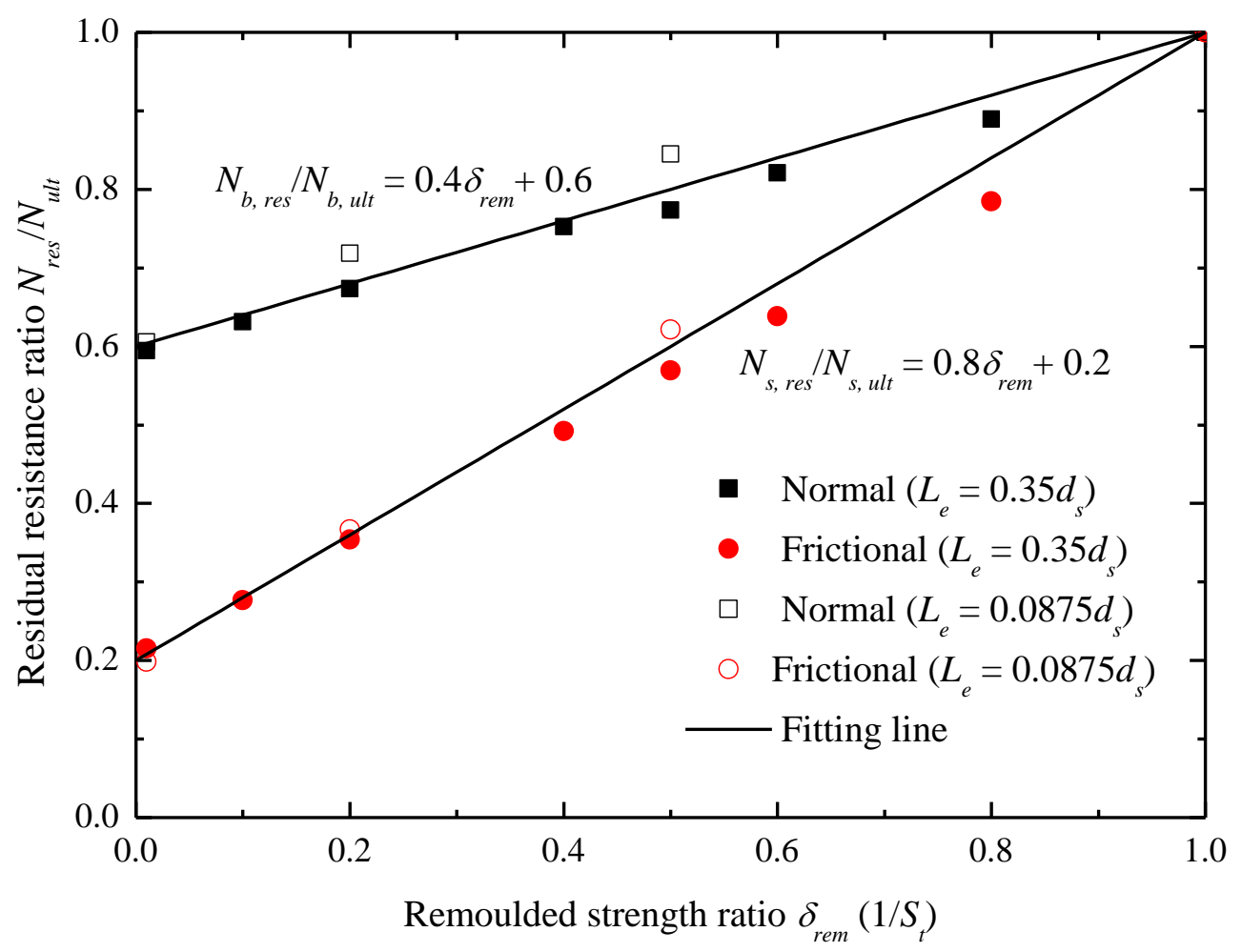

Figure 4. Residual capacity ratios of the embedded chain model 


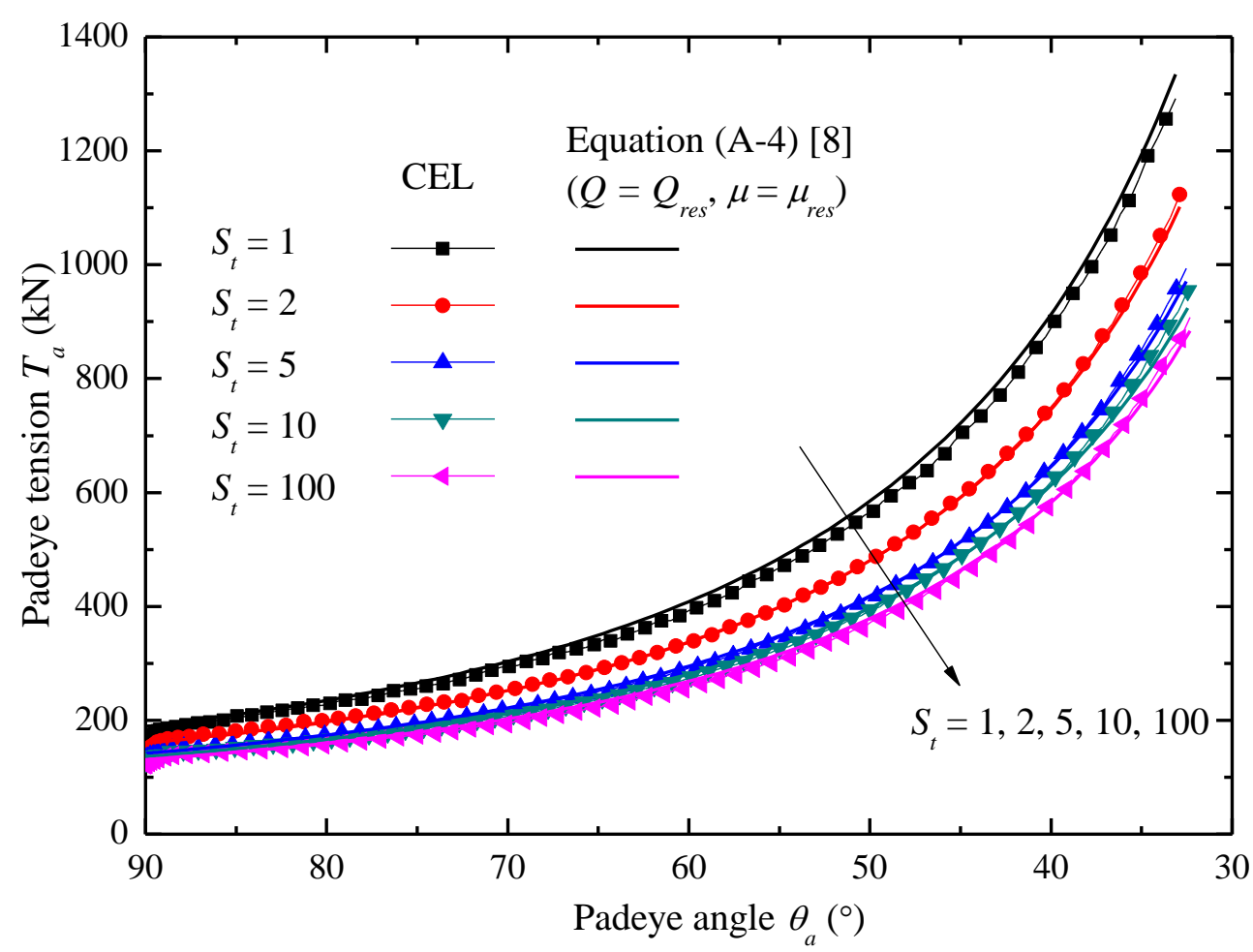

591 Figure 5. Comparison of tension-padeye angle relationships with different soil sensitivities 


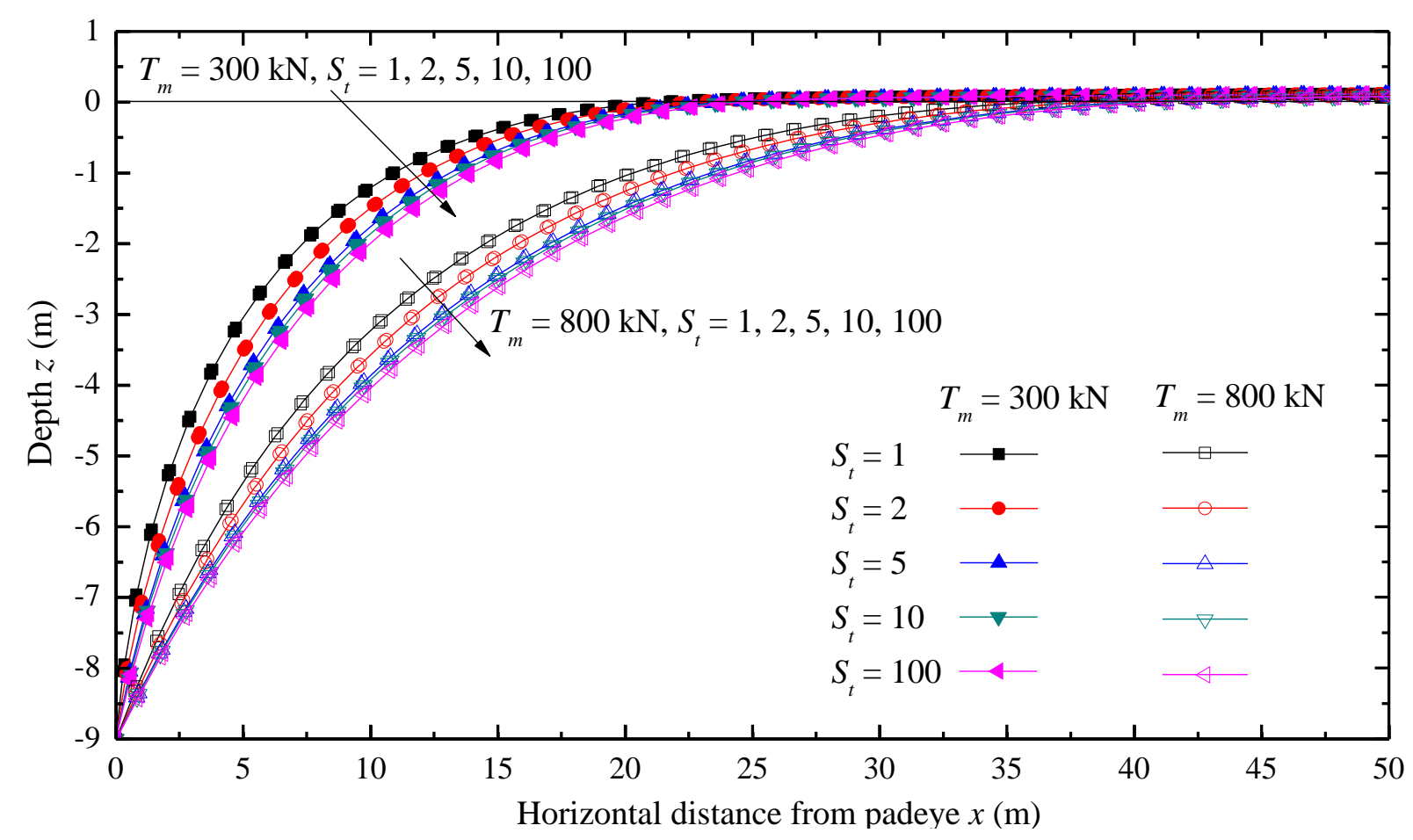

Figure 6. Chain profiles for different soil sensitivities at two mudline tensions 


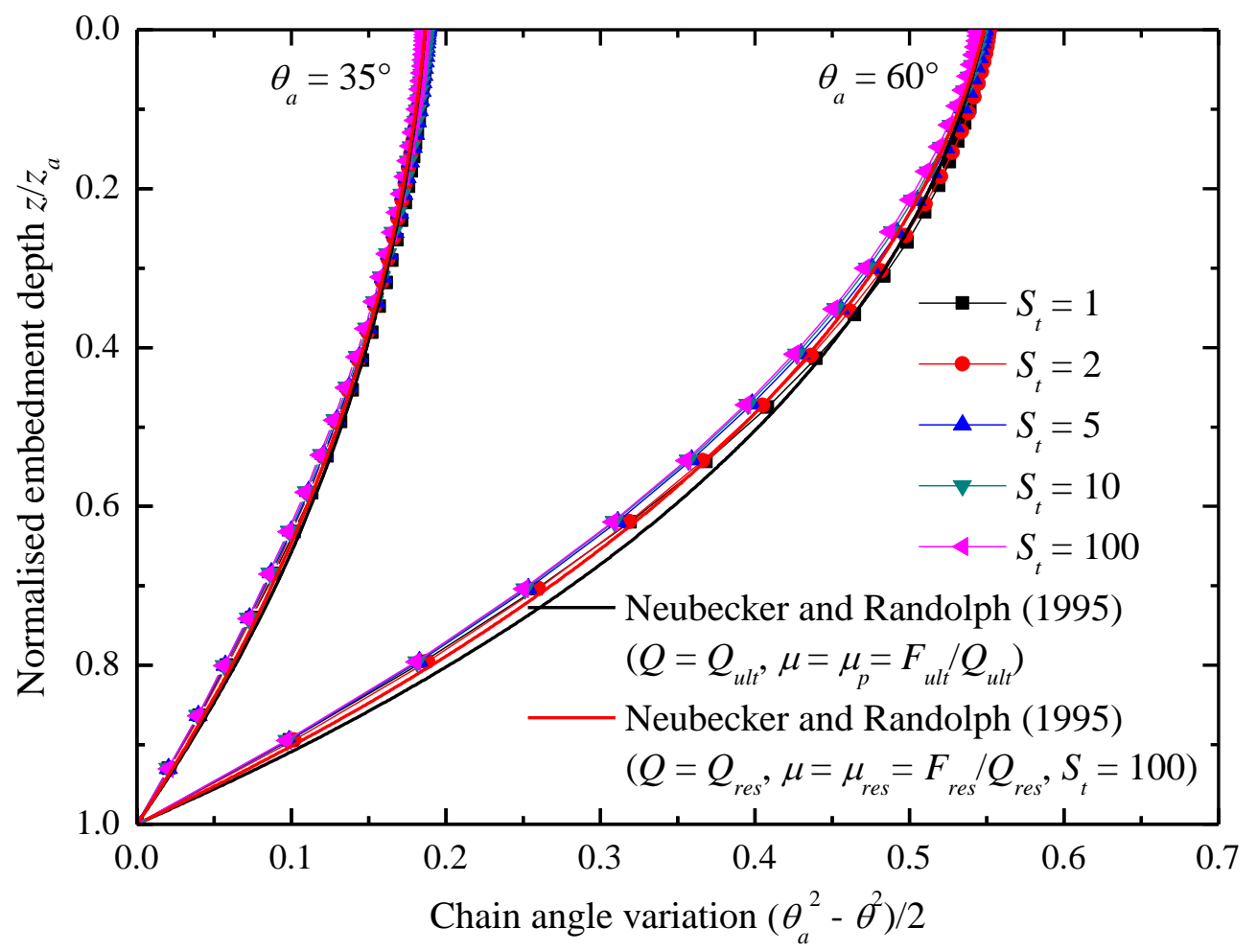

Figure 7. Comparison of the configurations of the embedded chain for selected chain inclination angles 


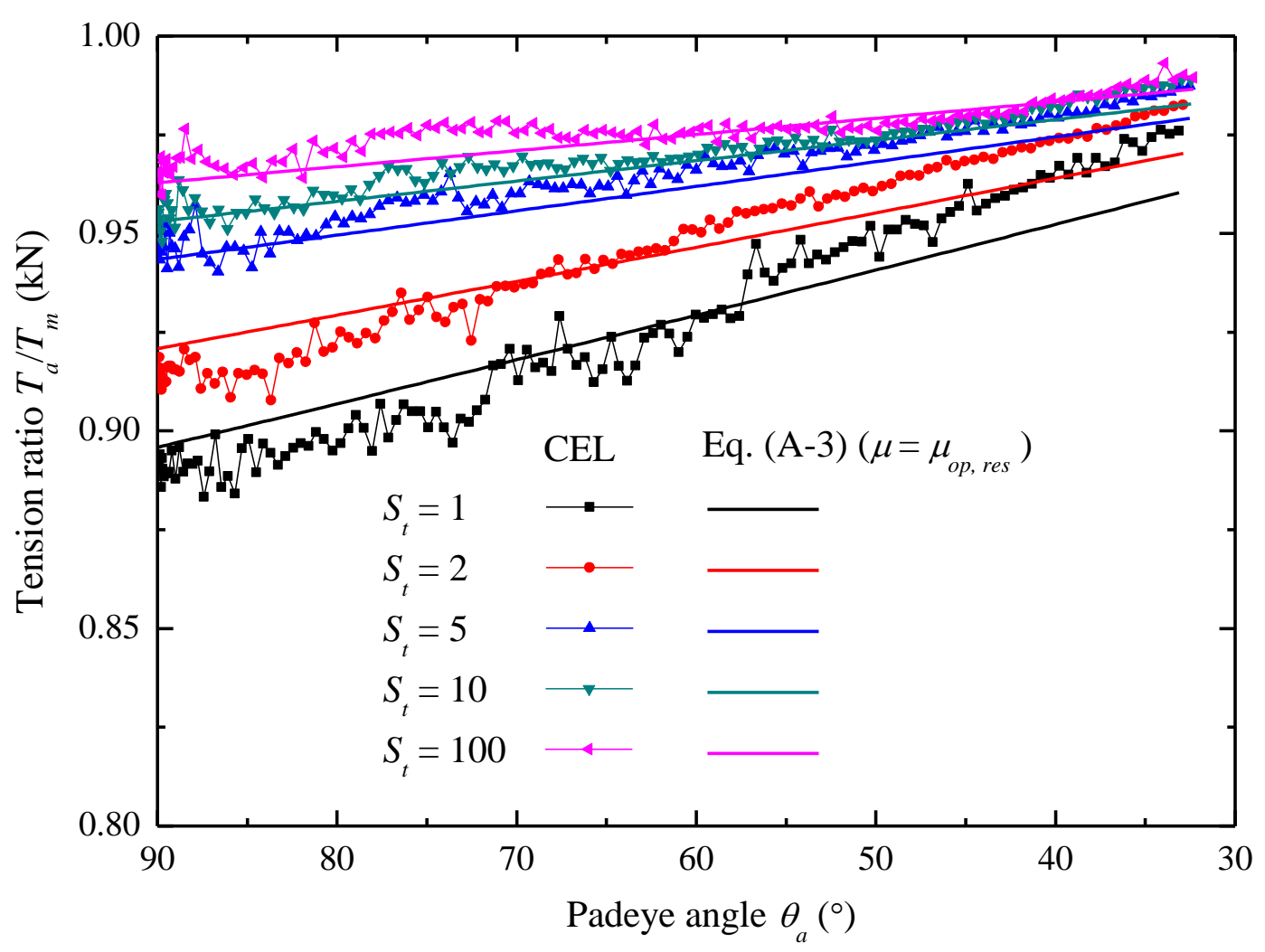

Figure 8. Comparison of tension ratio-padeye angle relationships with different soil sensitivities 


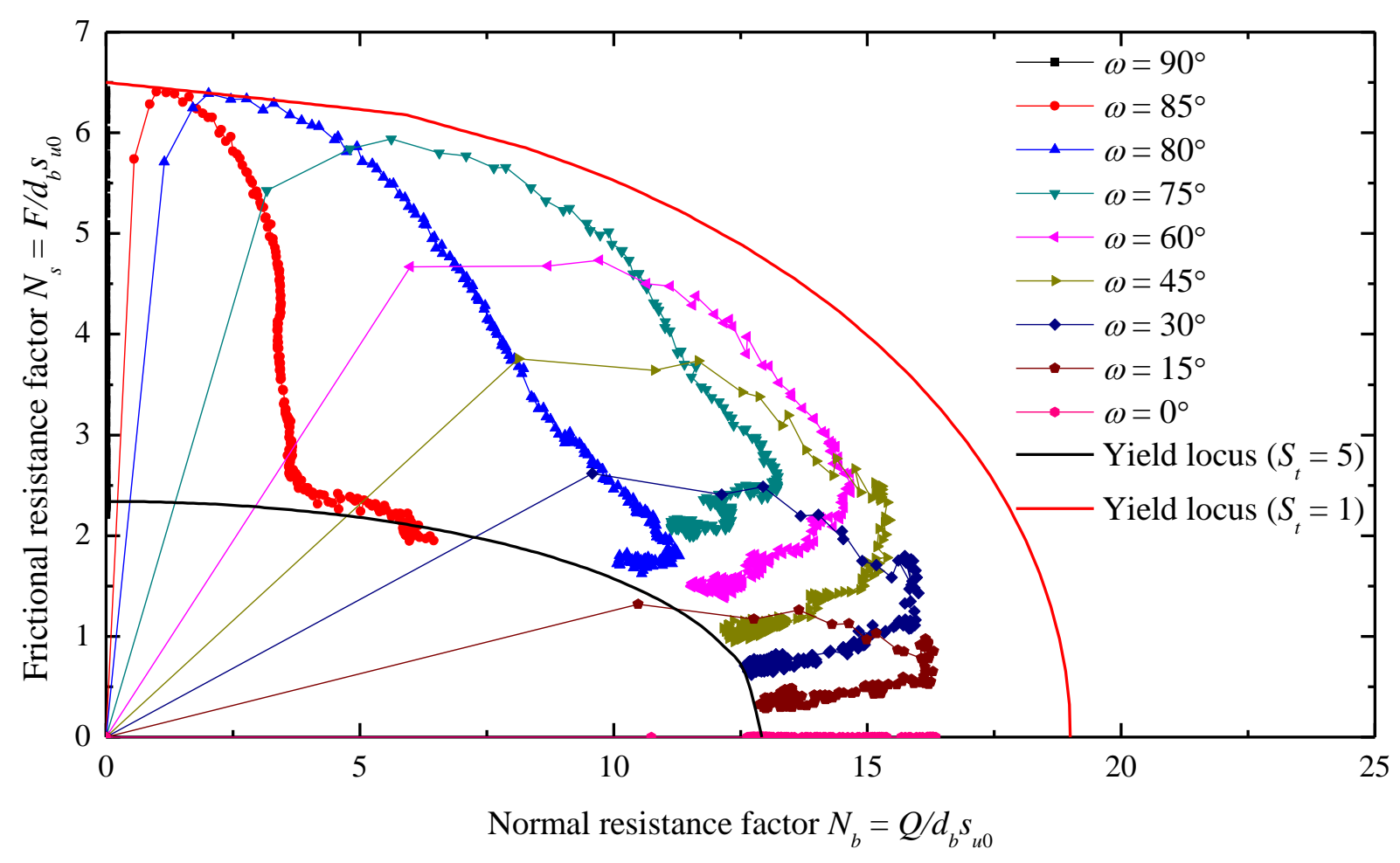

601

Figure 9. Probe testing results for $S t=5$ 

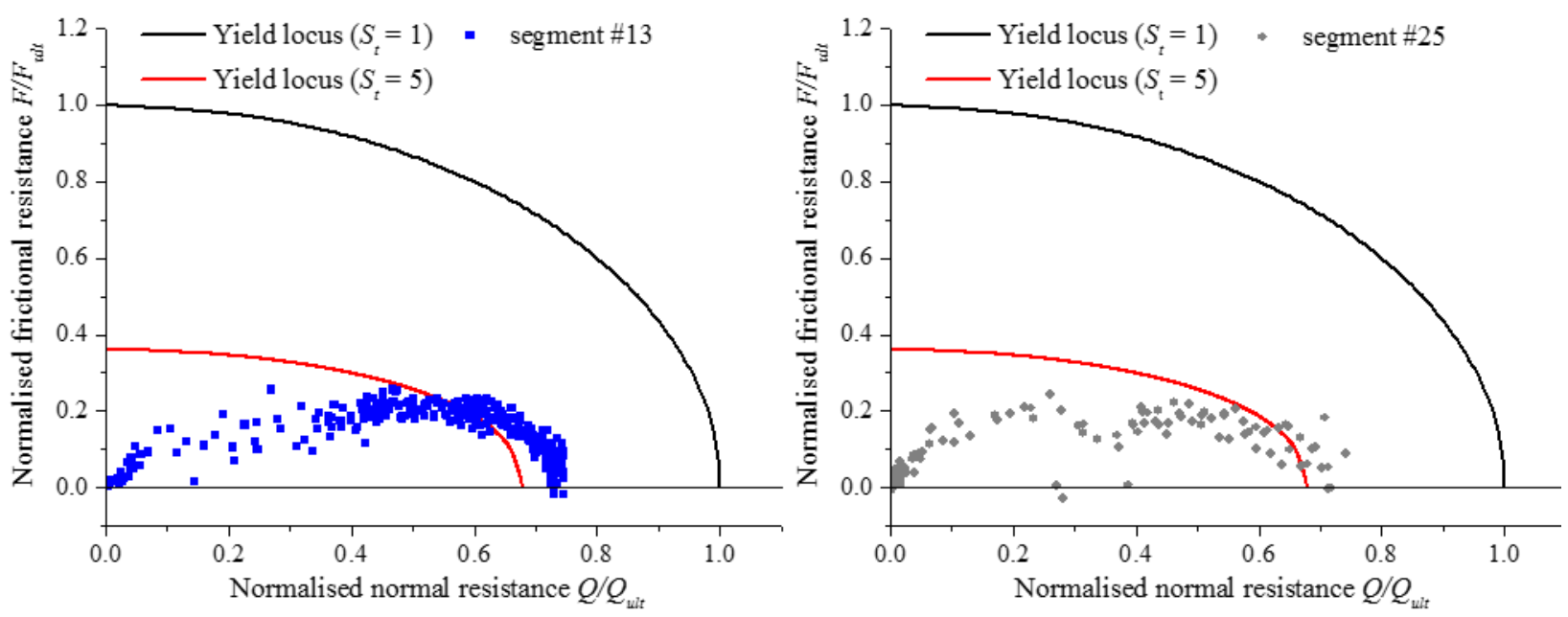

603 Figure 10. Evolution of the soil resistances to representative chain segments to tensioning (St 


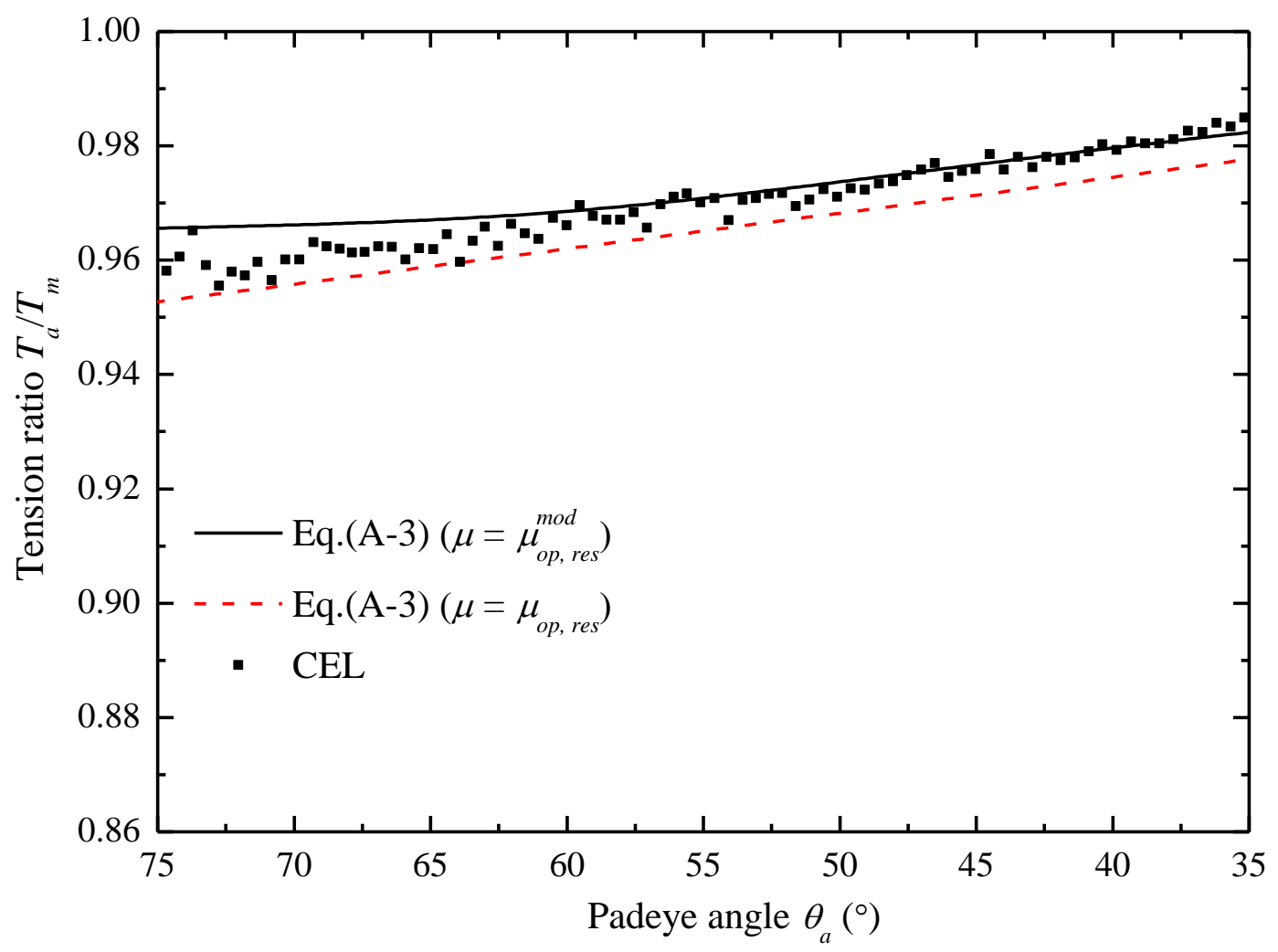

606 Figure 11. Tension ratio Ta/Tm calculated with modified operative frictional coefficient 607 


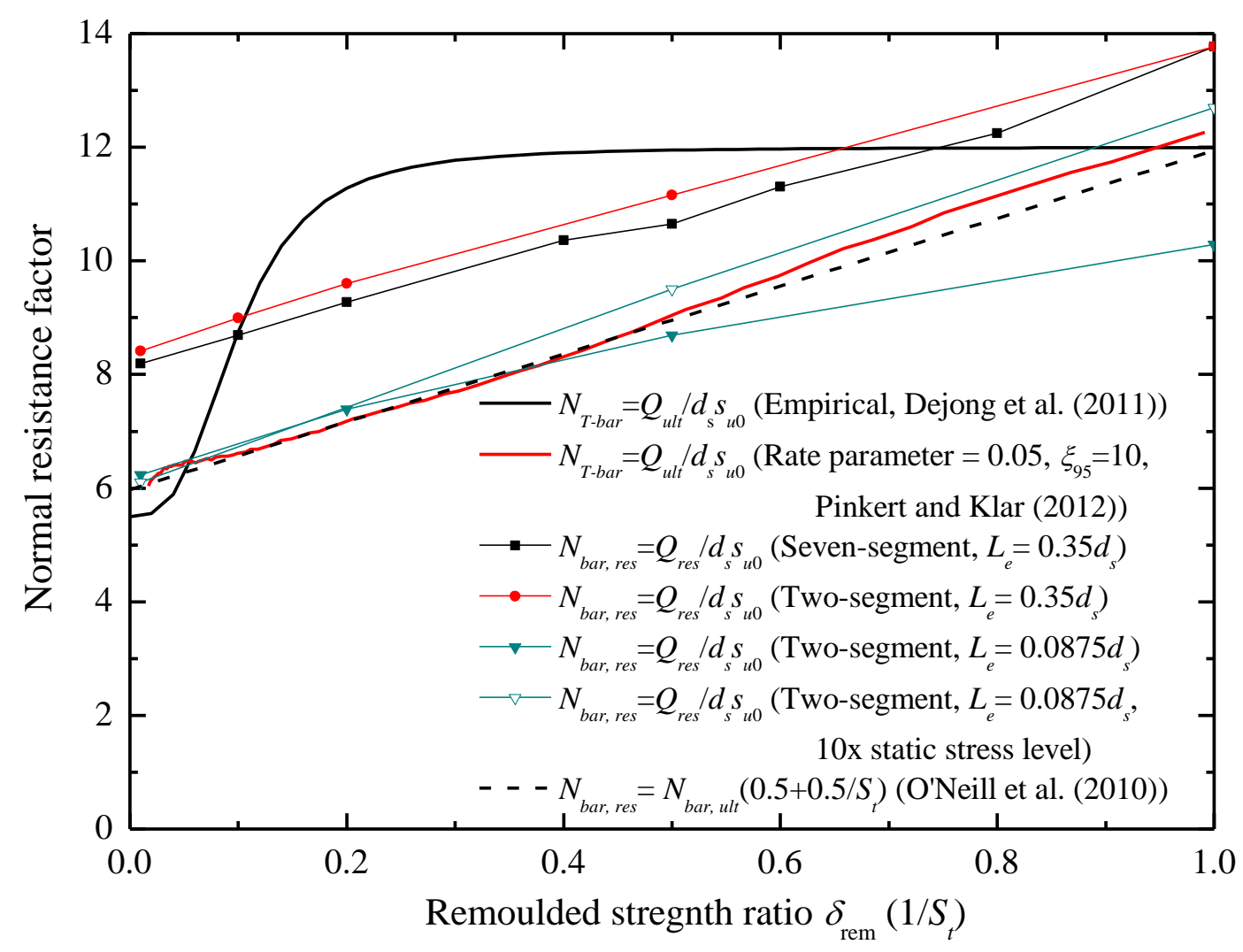

